CLINICAL STUDY

\title{
Metabolic follow-up after long-term pancreas graft survival
}

\author{
Christoph D Dieterle, Helmut Arbogast ${ }^{1}$, Wolf-Dieter Illner ${ }^{1}$, Susanne Schmauss and Rüdiger Landgraf \\ ${ }^{1}$ Diabetes Centre, Medizinische Klinik Innenstadt, University of Munich, 80336 Munich, Germany, ${ }^{2}$ Transplant Surgery, Department of Surgery, \\ Klinikum Grosshadern, University of Munich, 81377 Munich, Germany
}

(Correspondence should be addressed to C D Dieterle; Email: christoph.dieterle@med.uni-muenchen.de)

\begin{abstract}
Design: Successful pancreas transplantation results in insulin independence and normoglycemia. This prospective study was performed to investigatelong-term metabolic changes after pancreastransplantation. Methods: Thirty-eight type 1 diabetic patients after simultaneous pancreas/kidney transplantation (SPK) with a pancreas graft survival for at least 10 years were studied in a prospective manner. $\mathrm{HbA}_{1 \mathrm{c}}$ and glucose levels before and during an oral glucose tolerance test (OGTT) were analyzed from 3 months to 10 years after SPK. In addition, insulin secretion and glucagon response were measured.

Results: Fasting glucose increased slightly and continuously from 3 months to 10 years (from $78 \pm 3$ to $91 \pm$ $2 \mathrm{mg} / \mathrm{dl}$ ). Even $\mathrm{HbA}_{1 \mathrm{c}}$ levels showed a mild but significant increase from 3 months to 10 years after SPK. Glucose tolerance deteriorated markedly 10 years after SPK. Insulin secretion during OGTT remained stable for 10 years. Parameters of insulin resistance and sensitivity did not change significantly but glucagon secretion increased significantly during the course after SPK. Late after SPK, glucagon levels were higher in patients with an impaired or diabetic glucose tolerance.

Conclusions: Pancreas transplantation is able to restore endogenous insulin secretion for 10 years or more. Especially, late after SPK, a deterioration of glycemic control was detected, even if glucose values were within the normal range. During prospective long-term follow-up, an increase of glucagon secretion but no decrease of insulin secretion was detected.
\end{abstract}

European Journal of Endocrinology 156 603-610

\section{Introduction}

Simultaneous pancreas/kidney transplantation (SPK) should be the procedure of choice for (pre)uremic patients with type 1 diabetes (1-3) and should be preferred to kidney transplantation alone (KTA), since long-term studies demonstrated an advantage of SPK compared with KTA concerning patient mortality and graft survival rate (4-7). An alternative therapeutic option with comparable outcome concerning mortality is pancreas after kidney transplantation, preferably after living donor kidney transplantation (8).

Pancreas transplantation is able to sustain an insulinindependent state in type 1 diabetic patients (9). However, glucose metabolism and secretory capacity of pancreas grafts are not comparable to healthy individuals. Several factors are responsible for this: the long duration of diabetes before transplantation and the existence of autonomic neuropathy in most of the patients; the transplantation of a denervated pancreas; the systemic drainage of the endocrine part of pancreas graft; the immunosuppressive therapy after transplantation and a potentially reduced islet cell mass in the grafted pancreas due to rejection episodes; and loss of endocrine cells during the perioperative period (ischemia, infections).
Several studies have shown long-term pancreas graft survival $(4,10-13)$. However, little information is available regarding the long-term metabolic consequences of pancreas transplantation, especially scarce are prospective data on glucose metabolism and islet function. The aim of this prospective study was to investigate glucose metabolism of pancreas graft recipients who were free of exogenous insulin and had normal $\mathrm{HbA}_{1 \mathrm{c}}$ levels. This investigation examines fasting glucose, glucose tolerance after an oral glucose tolerance test, insulin secretion, insulin resistance, and glucagon secretion up to 10 years after SPK.

\section{Materials and methods}

\section{Study population}

Type 1 diabetic patients, who were insulin independent for at least 10 years after SPK, were investigated prospectively. Between 1982 and 1995 (suitable for 10-year follow-up), 167 SPKs were performed in the Munich transplantation center. Four patients were lost to complete long-term follow-up. The 10-year pancreas graft survival rate (defined as no need for exogenous insulin) in the remaining recipients was $28 \%(n=45)$. 
In 38 of the 45 patients, a complete metabolic follow-up for prospective studies was available. Patients with a loss of graft function or need for exogenous insulin were not studied.

Patients were investigated regularly after SPK at our outpatient clinic. Data of all patients were analyzed 3 months, 1, 3, 5 and 10 years after SPK. All graft recipients gave their informed consent. The first investigation, 3 months after transplantation, was only performed when graft function was stable with no rejection therapy during the last weeks before the test.

Clinical and demographic characteristics of the graft recipients are shown in Table 1 . Immunosuppressive treatment was initially performed with cyclosporine as first-line drug. During the course of follow-up, one patient was switched to tacrolimus, whereas one received a calcineurin inhibitor-free immunosuppression. In addition, all patients initially received azathioprine antimetabolite. Later, 14 patients were switched to mycophenolate mofetil and 6 received no antimetabolite for immunosuppression. All patients were treated with methylprednisolone early after SPK, 10 years after SPK glucocorticoids were withdrawn in $76 \%$. The rest of the patients received small amounts of methylprednisolone (2-4 mg/day). All patients received antithymocyte globulin (ATG) as an induction immunotherapy.

Patients received either a 'whole organ' with bladder drainage of the exocrine part of pancreas graft $(n=22)$ or a prolamine duct-occluded segmental pancreas graft $(n=16)$. All recipients had a systemic venous drainage of the islet hormones.

\section{Experimental studies}

All clinical studies and laboratory assays were performed in the laboratory of the same investigator. During each visit to our outpatient clinic, graft function was

Table 1 Clinical and demographic data of graft recipients with 10 years pancreas graft survival (mean \pm S.E.M.).

\begin{tabular}{lr}
\hline & 10-year follow-up \\
\hline$n$ & 38 \\
Male/female & $19 / 19$ \\
Age at transplantation (years) & $38 \pm 1$ \\
Duration of diabetes (years) & $25 \pm 1$ \\
Duration of dialysis (months) & $28 \pm 1$ \\
Surgical technique & 22 \\
$\quad$ Whole organ & 16 \\
Segmental & \\
Immunosuppression initial (\%) & 100 \\
Cyclosporine & 95 \\
Azathioprine & 100 \\
Methylprednisolone & 5 \\
Mycophenolate mofetil & \\
Immunosuppression at last follow-up (\%) & 95 \\
Cyclosporine & 58 \\
Azathioprine & 21 \\
Mycophenolate mofetil & 32 \\
Methylprednisolone & 3 \\
Tacrolimus & \\
\hline
\end{tabular}

monitored. After an overnight fast in the absence of the immunosuppressants or other drugs, serum creatinine and $\mathrm{HbA}_{1 \mathrm{c}}$ were measured and a glucose tolerance test was performed: $100 \mathrm{~g}$ glucose (i.e. $300 \mathrm{ml}$ Dextro-OGT, Roche Diagnostics) was ingested within 5 min. For blood sampling of glucose, glucagon and insulin, an i.v. line was placed, and blood samples were taken before (0 min) as well as 30,60 and 120 min after glucose load. Since in the early investigations $100 \mathrm{~g}$ glucose were used for testing the glucose utilization, all patients received this dose of glucose for comparison. Although $100 \mathrm{~g}$ glucose were the World Health Organization (WHO) criteria (14) for OGTT, $75 \mathrm{~g}$ were used to group patients. According to the WHO criteria for whole blood, the glucose tolerance test was defined as normal (NGT) if $2 \mathrm{~h}$ venous whole blood glucose was $<120 \mathrm{mg} / \mathrm{dl}(6.7 \mathrm{mmol} / \mathrm{l})$, as impaired (IGT) if between 120 and $179 \mathrm{mg} / \mathrm{dl}$ (6.7-10 mmol/l), and diabetic (DGT) if $2 \mathrm{~h}$ blood glucose was $180 \mathrm{mg} / \mathrm{dl}(10.0 \mathrm{mmol} / \mathrm{l})$ or higher. Since fasting glucose was normal in nearly all patients, graft recipients were only grouped according to the results of OGTT.

Insulin and glucagon secretion was characterized with area under the curve (AUC) for insulin secretion during OGTT. Areas under the curve were calculated using a trapezoidal method for glucose-stimulated insulin and glucagon concentration from 0 to $120 \mathrm{~min}$. Incremental insulin and glucose response were calculated as the difference between the values $30 \mathrm{~min}$ after glucose intake and those before glucose intake. In addition, AUCs for insulin and incremental insulin response were normalized to the glucose $\left(\mathrm{AUC}_{\mathrm{insulin}} / \mathrm{AUC}_{\text {glucose }}\right.$; $\Delta \mathrm{I}_{30} / \Delta \mathrm{G}_{30}$ ), as suggested by Jensen et al. (15). Insulin resistance index was calculated with the homeostasis model assessment of insulin resistance (HOMA) (fasting glucose $\times$ fasting insulin/22.5) (16). Insulin sensitivity was determined by the Matsuda-deFronzo index (10 000/ sqrt ((fasting glucose $\times$ fasting insulin) (mean glucose $X$ mean insulin)) (17).

\section{Analytical tests}

An automated glucose analyzer was used to determine glucose levels. $\mathrm{HbA}_{1 \mathrm{c}}$ was measured by HPLC (upper limit $6.0 \%$ ). Insulin and glucagon levels were determined by standard RIA (insulin: sensitivity $1 \mu \mathrm{U} / \mathrm{ml}$, coefficient of variation (CV) 6\%; glucagon: sensitivity $14.5 \mathrm{pg} / \mathrm{ml}, \mathrm{CV}$ 9\%).

\section{Calculations and statistical analysis}

Data are expressed as mean \pm s.E.M. To investigate changes in graft function from 3 months to 10 years, i.e. 10 years after SPK, ANOVA with repeated measurements was performed. For cross-sectional studies, groups were compared using Kruskal-Wallis test followed by Mann-Whitney $U$ test, if appropriate. Calculations were performed in cooperation with 
biostatisticians of the University of Munich. Statistical significance was defined as $P<0.05$.

\section{Results}

\section{Clinical characteristics}

Table 1 displays clinical and demographic data of the graft recipients with 10 years pancreas graft survival. Patients display a significant increase in body mass index (BMI) levels during the follow-up period (Table 2).

\section{Fasting glucose and $\mathrm{HbA}_{1 \mathrm{c}}$}

Fasting blood glucose values increased slightly and continuously after SPK from 3 months to 10 years after transplantation. A significant increase of fasting blood glucose compared with 3-month values post-transplant was detected from the fifth year onward. Also, $\mathrm{HbA}_{1 \mathrm{c}}$ levels showed a mild deterioration during the long-term follow-up after SPK. A significant increase was detectable in the first year as well as 10 years after SPK (Table 2).

\section{OGTT}

In total, $33 \%$ of patients with 10-year graft survival displayed an impaired or diabetic glucose tolerance already 3 months after transplantation. Until 5 years post-transplant, the rate of a normal glucose tolerance was similar. Ten years after SPK, only $37 \%$ of graft recipients showed a normal glucose tolerance (Table 2). A normal glucose tolerance was accompanied by significant lower fasting glucose values. This was true for every time point after transplantation. $\mathrm{HbA}_{1 \mathrm{c}}$ values were also significantly lower in patients with NGT. Table 3 shows the results of the cross-sectional analyses for 10 years after SPK. Comparable results were found at each time point of the follow-up.

\section{Insulin secretion}

There were no significant changes in fasting insulin during the course after SPK (Table 2). Insulin release due to glucose $\left(\mathrm{AUC}_{\text {insulin }}\right.$ and $\left.\mathrm{AUC}_{\text {insulin }} / \mathrm{AUC}_{\text {glucose }}\right)$ was very similar in the prospective evaluation, no decrease of the secretory capacity of the grafted pancreata was detected. Subgroup analysis of patients displaying a normal glucose tolerance did not also reveal timedependent changes in insulin secretion (AUC for insulin and AUC insulin normalized to glucose, Fig. 1). Analysis of incremental insulin response in NGT patients did show a time-dependent reduction during the first 5 years after transplantation; however, these changes were not significant (Fig. 2).

Cross-sectional analyses revealed a reduced insulin secretion in patients with an impaired or diabetic glucose tolerance at any time point, except 3 months after SPK (Fig. 1, Table 3, data shown are only for 10 years after SPK). This was supported by the determination of the incremental response showing significantly reduced early insulin responses in graft recipients with IGT and DGT (Fig. 2).

The HOMA-IR and the Matsuda-deFronzo index did not change from 3 months to 10 years after SPK (Table 2). Cross-sectional analysis did not reveal significant differences in the parameters of insulin resistance and insulin sensitivity between different grades of glucose tolerance (Table 3 ).

\section{Glucagon secretion}

Neither early nor late after SPK was glucagon secretion inhibited by glucose (Fig. 3). Ten years after SPK was glucagon even paradoxically stimulated by glucose. Prospective analyses showed significantly higher glucagon levels after glucose load at 10 years after SPK in comparison with 3 months after SPK (Fig. 3). Furthermore, glucagon secretion $\left(\mathrm{AUC}_{\text {glucagon }}\right)$ increased significantly during the follow-up after SPK (Fig. 4). Crosssectional analysis revealed a significantly higher

Table 2 Parameters of pancreas and kidney graft function from 3 months to 10 years after simultaneous pancreas/kidney transplantation.

\begin{tabular}{|c|c|c|c|c|c|c|}
\hline & $\begin{array}{r}3 \text { months } \\
(n=38)\end{array}$ & $\begin{array}{r}1 \text { year } \\
(n=38)\end{array}$ & $\begin{array}{l}3 \text { years } \\
(n=38)\end{array}$ & $\begin{array}{l}5 \text { years } \\
(n=38)\end{array}$ & $\begin{array}{r}10 \text { years } \\
(n=38)\end{array}$ & $\boldsymbol{P}$ \\
\hline Fasting blood glucose (mg/dl) & $78 \pm 2$ & $81 \pm 2$ & $82 \pm 2$ & $84 \pm 2$ & $91 \pm 2$ & $<0.01^{\mathrm{a}, \mathrm{b}, \mathrm{c}, \mathrm{d}, \mathrm{e}}$ \\
\hline $\mathrm{HbA}_{1 \mathrm{c}}(\%)$ & $4.6 \pm 0.1$ & $4.9 \pm 0.1$ & $4.9 \pm 0.1$ & $5.0 \pm 0.1$ & $5.3 \pm 0.2$ & $<0.001^{\mathrm{f}, \mathrm{a}, \mathrm{b}, \mathrm{d}, \mathrm{g}, \mathrm{h}}$ \\
\hline 120 min glucose $(\mathrm{mg} / \mathrm{dl})$ & $118 \pm 7$ & $122 \pm 9$ & $110 \pm 9$ & $118 \pm 9$ & $150 \pm 13$ & $<0.05^{\mathrm{d}, \mathrm{g}, \mathrm{i}}$ \\
\hline Normal glucose tolerance (\%) & 67 & 56 & 68 & 66 & $\overline{37}$ & $<0.05^{\mathrm{b}, \mathrm{g}, \mathrm{i}}$ \\
\hline BMI $\left(\mathrm{kg} / \mathrm{m}^{2}\right)$ & $21.1 \pm 0.4$ & $21.9 \pm 0.5$ & $22.4 \pm 0.5$ & $22.8 \pm 0.5$ & $23.5 \pm 0.7$ & $<0.05^{\mathrm{j}, \mathrm{a}, \mathrm{b}, \mathrm{c}, \mathrm{d}, \mathrm{g}}$ \\
\hline Fasting insulin $(\mu \mathrm{U} / \mathrm{ml})$ & $21 \pm 2$ & $23 \pm 2$ & $18 \pm 1$ & $18 \pm 1$ & $16 \pm 1$ & $<0.05^{\mathrm{d}}$ \\
\hline $\mathrm{AUC}_{\text {insulin }}(\mu \mathrm{U} / \mathrm{ml} \times \mathrm{min})$ & $11735 \pm 1365$ & $11754 \pm 985$ & $11215 \pm 886$ & $11801 \pm 995$ & $11772 \pm 1074$ & $t \quad \mathrm{Ns}$ \\
\hline Incremental insulin $\Delta \mathrm{I}_{30} / \Delta \mathrm{G}_{30}(\mu \mathrm{U} / \mathrm{ml})$ & $221 \pm 50$ & $176 \pm 28$ & $157 \pm 28$ & $157 \pm 22$ & $168 \pm 36$ & Ns \\
\hline HOMA-IR & $4.1 \pm 0.4$ & $4.5 \pm 0.5$ & $3.7 \pm 0.3$ & $3.7 \pm 0.3$ & $3.5 \pm 0.3$ & Ns \\
\hline Matsuda-deFronzo ISI & $3.6 \pm 0.4$ & $2.9 \pm 0.2$ & $3.5 \pm 0.3$ & $3.1 \pm 0.2$ & $3.2 \pm 0.3$ & Ns \\
\hline S-creatinine & $1.3 \pm 0.1$ & $1.3 \pm 0.1$ & $1.4 \pm 0.1$ & $1.5 \pm 0.1$ & $1.5 \pm 0.1$ & Ns \\
\hline
\end{tabular}

Mean \pm S.E.M. ANOVA with repeated measurements.

${ }^{a} 3$ months versus 5 years. ${ }^{b} 3$ months versus 10 years. ${ }^{c} 1$ year versus 5 years. ${ }^{d} 1$ year versus 10 years. ${ }^{e_{1}}$ year versus 3 years. ${ }^{f} 3$ months versus 1 year. ${ }^{g} 3$ years versus 10 years. ${ }^{h_{3}}$ years versus 5 years. ${ }^{i} 5$ years versus 10 years. ${ }^{j} 3$ months versus 3 years. 
Table 3 Metabolic data during fasting and an OGTT 10 years after simultaneous pancreas/kidney transplantation.

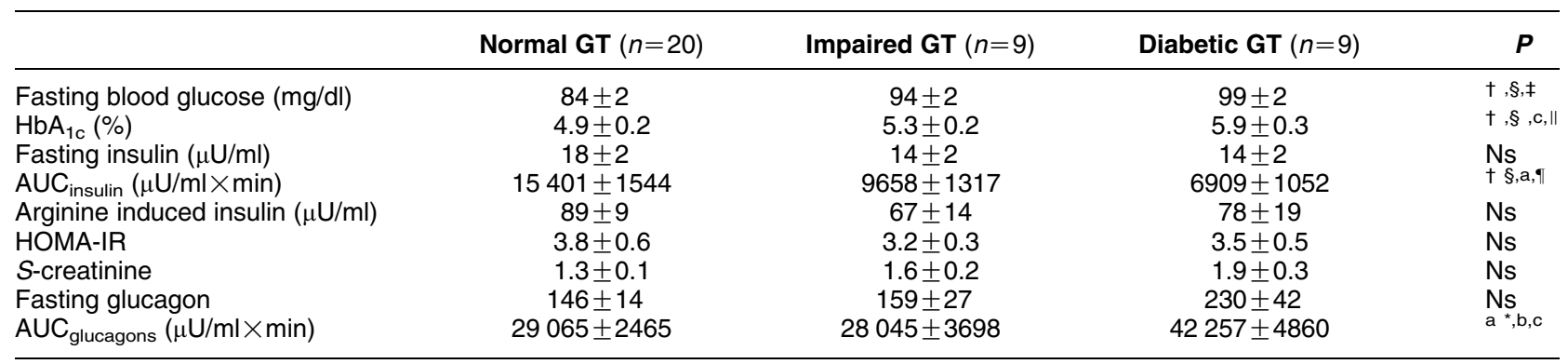

NGT versus DGT: ${ }^{\star} P<0.05 ;{ }^{\dagger} P<0.01 ;{ }^{\ddagger} P<0.001$; NGT versus IGT: ${ }^{\circledR} P<0.05 ; " ~ P P<0.01 ;{ }^{\mathrm{t}} P<0.001 ;$ IGT versus DGT: ${ }^{\mathrm{a}} P<0.05 ;{ }^{\mathrm{b}} P<0.01 ;{ }^{\mathrm{c}} P<0.001$; mean \pm S.E.M.

glucagon secretion in graft recipients with diabetic glucose tolerance 5 and 10 years after SPK (Fig. 5).

\section{Whole organ versus segmental graft}

Patients who received a segmental graft were compared with recipients of a whole organ in a crosssectional manner. Table 4 shows the data for 1 and 10 years after SPK. Fasting glucose and $\mathrm{HbA}_{1 \mathrm{c}}$ levels were always higher in patients who received segmental graft, and significant differences were only found early after SPK. Patients with a whole organ graft had more often a significant normal glucose tolerance. Insulin secretion (AUC for insulin, insulin response corrected for glucose, and incremental insulin response) was significantly higher in recipients of a whole organ (Table 4; Fig. 6). Early after SPK, the glucagon secretion was higher in whole organ recipients. Late after SPK, glucagon levels were similar; however, a time-dependent increase of glucagon secretion was observed in both techniques.

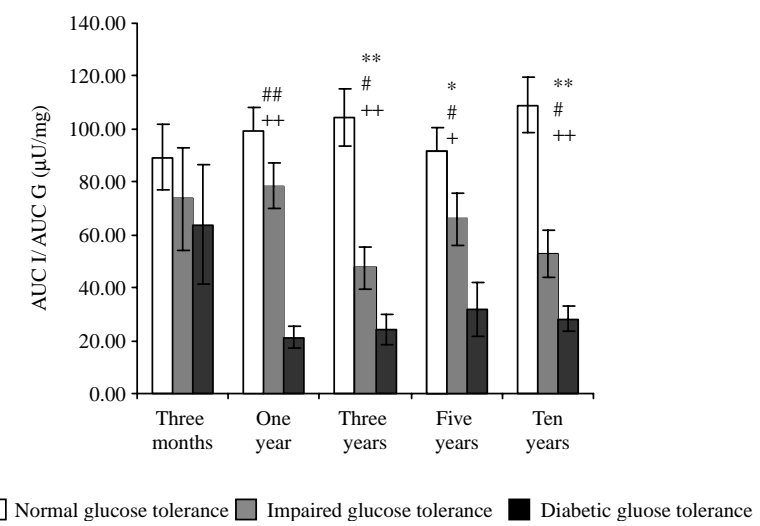

Figure 1 Insulin secretion (normalized to glucose) in graft recipients with normal, impaired and diabetic glucose tolerance from 3 months to 10 years after SPK NGT vs. IGT: ${ }^{\star} P<0.05 ;{ }^{\star \star} P<0.01 ;{ }^{\star \star \star} P<$ 0.001 ; IGT vs. DGT: ${ }^{\#} P<0.05$; ${ }^{\# \# ~} P<0.01 ;{ }^{\# \#} P<0.001$; NGT vs. DGT: ${ }^{+} P<0.05 ;{ }^{+} P<0.01 ;{ }^{++}++0.001$; Mean \pm S.E.M.

\section{Discussion}

The aim of pancreas transplantation is to obtain longterm normoglycemia by restoring endogenous insulin secretion. The present study demonstrates pancreas graft survival for more than 10 years in a remarkable number of graft recipients (a 10-year pancreas graft survival rate of $28 \%$ might be considered as low; however, our analysis includes the early years of pancreas transplantation in the 1980s). Thus, pancreas transplantation is able to sustain normal blood glucose profiles and $\mathrm{HbA}_{1 \mathrm{c}}$ values for more than 10 years. It is important to note that some recipients of a segmental pancreas graft showed a long-term graft survival including normal glucose profiles despite a considerably reduced islet cell mass. In fact, our longest pancreas graft survivor $(>23$ years) with an excellent pancreas graft function received a prolamine duct-occluded segmental pancreas. However, segmental pancreas transplantation was abandoned in most transplant centers. Segmental pancreas transplantation might become important in the field of living donor

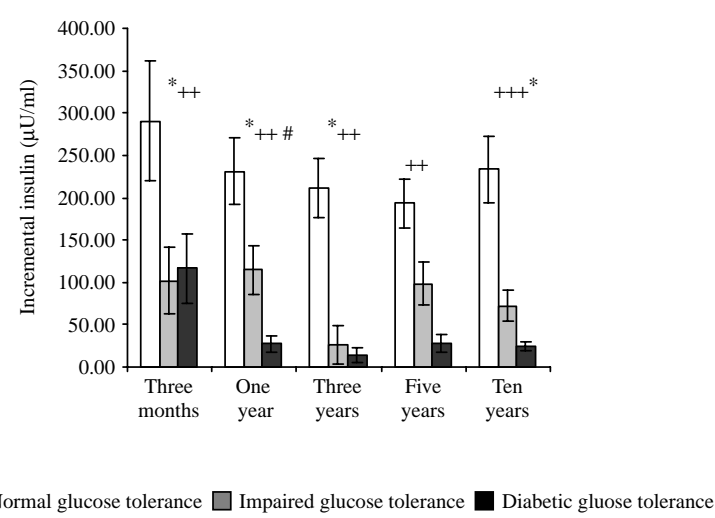

Figure 2 Incremental insulin response in patients with normal, impaired and diabetic glucose tolerance from 3 months to 10 years after SPK NGT vs. IGT: ${ }^{\star} P<0.05 ;{ }^{\star \star} P<0.01 ;{ }^{\star \star \star} P<0.001$; IGT vs. DGT: ${ }^{\#} P<0.05$; ${ }^{\#} P<0.01 ;{ }^{\# \# \#} P<0.001$; NGT vs. DGT: ${ }^{+} P<0.05$; ${ }^{++} P<0.01 ;+++P<0.001 ;$ Mean \pm S.E.M. 


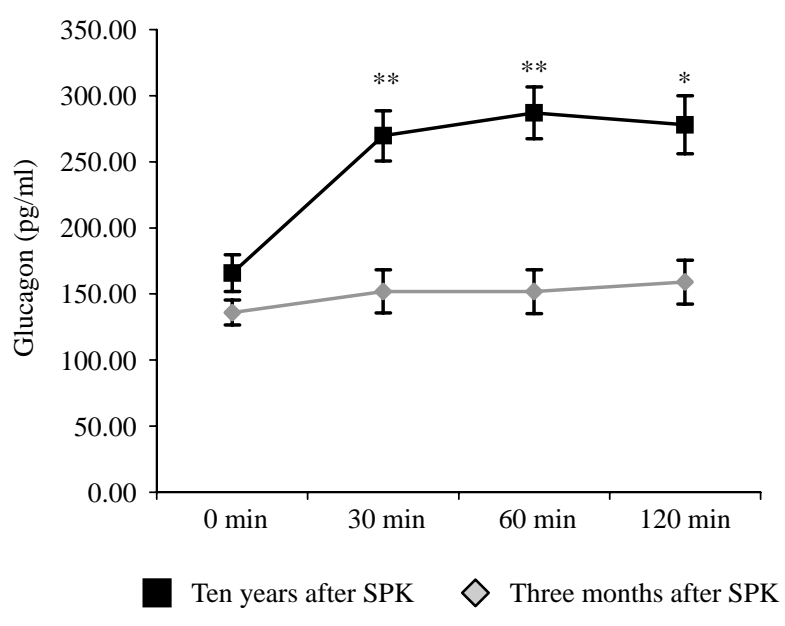

Figure 3 Glucagon level before and after glucose load 3 months and 10 years after SPK Mean \pm S.E.M.

transplantation (18). Even if our center does not perform living donor segmental pancreas transplants, our data prove the possibility of long-term survival of this technique in principle.

Despite stable graft function over years, a small but continuous increase of fasting glucose values was detected. Except the first year after transplantation, $\mathrm{HbA}_{1 \mathrm{c}}$ values remain stable within the normal range from 1 to 10 years after SPK. Long-term normalization of glucose values in pancreas graft recipients has been published recently (19). Another study has shown that 6 years after SPK, glucose control and blood glucose variability are superior to implantable insulin pumps (20). In this prospective study, the rate of a normal glucose tolerance was stable up to 5 years after SPK, followed by a distinct impairment of glucose utilization. The rate of impaired or diabetic glucose tolerance was higher compared with other studies $(21,22)$. This could be explained by the higher dosage of glucose load (100 g

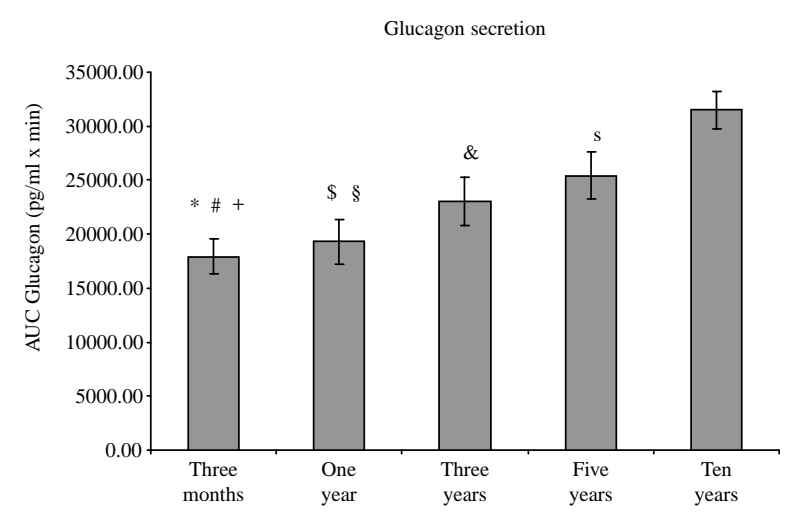

Figure $4 \mathrm{AUC}_{\text {glucagon }}(0-120 \mathrm{~min}$ ) before and after oral glucose load from 3 months to 10 years after SPK (mean \pm S.E.M.). $P<0.05$; ${ }^{\star} 3$ months vs. 3 years; ${ }^{+} 3$ months vs. 5 years; ${ }^{\#} 3$ months vs. 10 years; $\$_{1}$ year vs. 5 years; ${ }^{\$} 1$ year vs. 10 years; ${ }^{\&} 3$ years vs. 10 years ${ }^{s} 5$ years vs. 10 years.

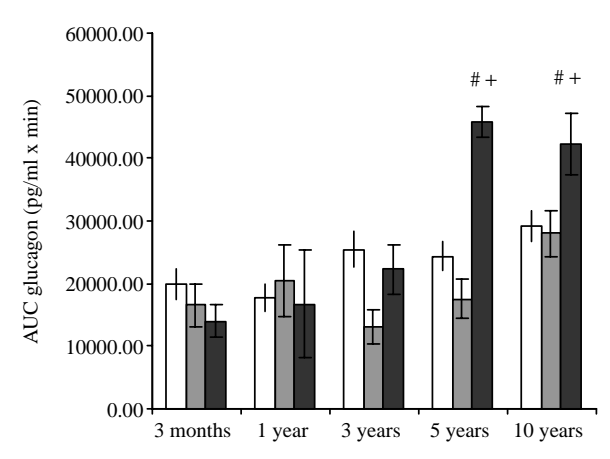

$\square$ Normal glucose tolerance $\square$ Impaired glucose tolerance $\square$ Diabetic gluose tolerance

Figure $5 \mathrm{AUC}_{\text {glucagon }}$ during OGTT (0-120 min) from 3 months to 10 years after SPK in patients with normal, impaired, and diabetic glucose tolerance (mean \pm s.E.M.) NGT vs. IGT: ${ }^{*} P<0.05$; ${ }^{* \star} P<$ 0.01 ; ${ }^{* \star} P<0.001$; IGT vs. DGT: ${ }^{\#} P<0.05$; ${ }^{\# \#} P<0.01$; ${ }^{\# \# \#} P<0.001$; NGT vs. DGT: ${ }^{+} P<0.05 ;{ }^{++} P<0.01 ;{ }^{++}+P<0.001$.

instead of $75 \mathrm{~g}$ ) in our study. Even if fasting glucose increased continuously, it remained within the normal range. $\mathrm{HbA}_{1 \mathrm{c}}$ did not deteriorate until 10 years after transplantation. Therefore, oral glucose tolerance seems to be a more sensitive marker of graft dysfunction than fasting blood glucose. Indeed, other studies have shown that an intact graft function 1 year after pancreas transplantation is predictive for graft survival at least up to 5 years post-transplant $(10,13)$. However, an impaired or diabetic glucose tolerance test does not necessarily result in later graft loss.

Up to 10 years after SPK, there was no change in insulin response to glucose. In patients with a long-term survival of the pancreas graft, no time-dependent decline in $\beta$-cell function could be detected. In principle, this may serve as a proof of unlimited long-term survival and function of grafted $\beta$ cells. This has not been shown after islet transplantation. The distinct worsening of glucose tolerance late after SPK was not accompanied by a significant time-dependent reduction in insulin release. Data retrieved only from patients with normal glucose tolerance support these results, since insulin secretion was stable also in this subgroup. However, slight differences were found concerning incremental insulin response. These results were not significant, probably due to the low patient number. However, if any early insulin secretion might be responsible for timedependent worsening of glucose metabolism.

The insulin secretion was indeed reduced in graft recipients with IGT or DGT, which was found early after transplantation. At every time point of the follow-up, an IGT or DGT was always accompanied by reduced insulin secretion. This reduction is consistent with the findings of Robertson et al. (19), who described a reciprocal relation between insulin secretion and glucose levels. However, our studies did not show a clear timedependent reduction in the secretory capacity. Thus, a reduced $\beta$-cell function could explain differences in 
Table 4 Parameters of pancreas and kidney graft function 1 year and 10 years after simultaneous pancreas/kidney transplantation. Segmental versus whole organ.

\begin{tabular}{|c|c|c|c|c|}
\hline & \multicolumn{2}{|c|}{1 year $(n=38)$} & \multicolumn{2}{|c|}{10 years $(n=38)$} \\
\hline & $\begin{array}{l}\text { Segmental } \\
(n=16)\end{array}$ & $\begin{array}{l}\text { Whole } \\
(n=22)\end{array}$ & $\begin{array}{l}\text { Segmental } \\
(n=16)\end{array}$ & $\begin{array}{l}\text { Whole } \\
(n=22)\end{array}$ \\
\hline Fasting blood glucose $(\mathrm{mg} / \mathrm{dl})$ & $85 \pm 2$ & $75 \pm 2^{*}$ & $91 \pm 2$ & $90 \pm 2$ \\
\hline $\mathrm{HbA}_{1 \mathrm{c}}(\%)$ & $5.0 \pm 0.2$ & $4.9 \pm 0.2$ & $5.4 \pm 0.2$ & $5.1 \pm 0.1$ \\
\hline $120 \mathrm{~min}$ glucose $(\mathrm{mg} / \mathrm{dl})$ & $132+14$ & $108+9$ & $169+20$ & $137+17^{*}$ \\
\hline Normal glucose tolerance (\%) & 41 & $63^{\dagger}$ & $25^{\ddagger}$ & $45^{\star}$ \\
\hline $\mathrm{AUC}_{\text {insulin }}(\mu \mathrm{U} / \mathrm{ml} \times \min )$ & $9650 \pm 1663$ & $14367 \pm 808^{*}$ & $9778 \pm 1546$ & $13161 \pm 1415^{\star}$ \\
\hline $\begin{array}{l}\text { Incremental insulin } \Delta \mathrm{I}_{30} / \Delta \mathrm{G}_{30} \\
(\mu \mathrm{U} / \mathrm{ml})\end{array}$ & $166 \pm 43$ & $189 \pm 33^{*}$ & $147 \pm 54$ & $193 \pm 44^{*}$ \\
\hline HOMA-IR & $4.8 \pm 0.4$ & $4.0 \pm 0.5$ & $3.3 \pm 0.3$ & $3.8 \pm 0.3$ \\
\hline Matsuda-deFronzo & $2.7 \pm 0.4$ & $3.1 \pm 0.2$ & $3.4 \pm 0.3$ & $3.1 \pm 0.2$ \\
\hline $\mathrm{AUC}_{\text {glucagons }}(\mathrm{pg} / \mathrm{ml} \times \mathrm{min})$ & $16376 \pm 2619$ & $22945^{\dagger} \pm 3153$ & $30994 \pm 2632$ & $32037 \pm 2398$ \\
\hline S-creatinine & $1.4 \pm 0.1$ & $1.3 \pm 0.1$ & $1.8 \pm 0.1^{*}$ & $1.5 \pm 0.1$ \\
\hline
\end{tabular}

Segmental versus whole organ technique. ${ }^{*} P<0.05 ;{ }^{\dagger} P>0.01 ;{ }^{\ddagger} P<0.001$.

glucose metabolism in the cross-sectional analysis but not in the prospective studies. In type 2 diabetes, a decrement of especially the postprandial insulin secretion determines the progressive nature of the disease $(23,24)$. A progressive reduction in insulin secretion was not found in grafted patients, at least not in those with long-term survival. However, even the stable secretory capacity of the grafted pancreas may protect these patients from a diabetic metabolism.

An increase of insulin secretion during the follow-up was not found. Matte et al. demonstrated an increase of insulin release of pancreas graft recipients up to 3 years after SPK. They assumed a progressive increase of insulin resistance (25). This could not be verified by our results, since there was no change in the insulin resistance index in the first 10 years after SPK, although BMI levels increased slightly significantly during the follow-up. Cross-sectional analysis revealed similar levels of insulin resistance and insulin sensitivity in patients with NGT, IGT, and DGT.

Glucose failed to suppress glucagon secretion in our patients. An inappropriate suppression by oral glucose in pancreas graft recipients has been reported by Christiansen et al. (21). The lack of suppression of glucagon was mostly found in patients with impaired glucose tolerance. Interestingly, glucagon secretion

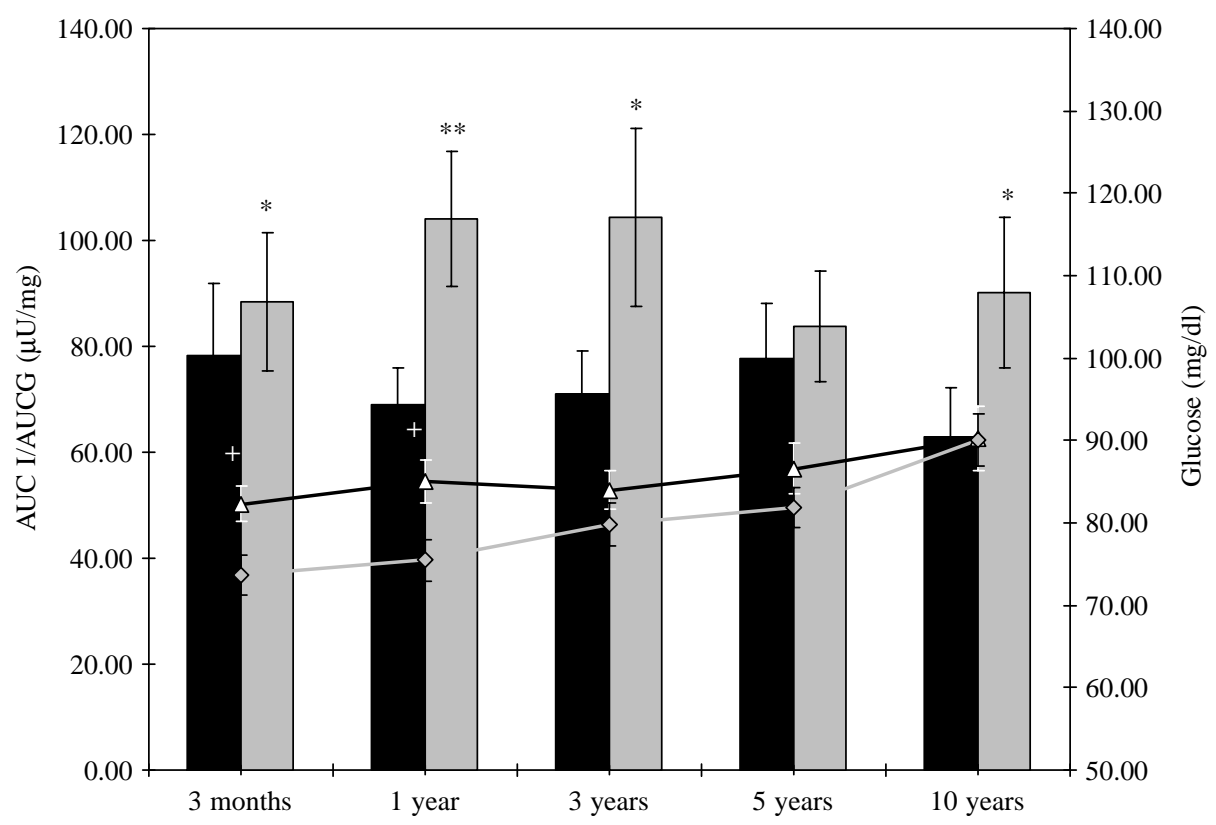

Figure 6 Insulin secretion ( $A \cup C_{\text {insulin }}$ 0-120 min, normalized to glucose) and fasting glucose values in either segmental or whole organ pancreas graft recipients from 3 months to 10 years after transplantation. Black columns:Insulin secretion, segmental graft recipients. Grey columns: Insulin secretion, whole organ graft recipients. Triangle symbol: glucose values, segmental graft recipients. Rhombus symbol:glucose values, whole organ graft recipients ${ }^{\text {a }} P<0.05$; ${ }^{\text {aa }} P>0.01$; ${ }^{\text {aaa }} P<0.001$. 
showed a significant and progressive increase over time. In addition, late after SPK, graft recipients with a diabetic glucose tolerance displayed significantly higher glucagon levels than patients with a normal glucose tolerance. Glucagon is usually extracted by the liver (26). Bypassing the first-pass effect of the liver leads to peripheral hyperglucagonemia in pancreas graft recipients with a systemic endocrine drainage. However, immunosuppression is also assumed to cause hyperglucagonemia, since similar glucagon levels were found in immunosuppressed non-diabetic recipients of a solitary kidney graft (21). Also, an impaired kidney function (i.e. a lower creatinine clearance) might contribute to higher glucagon levels in the blood. This is supported by the fact that patients with DGT did not only show higher glucagon but also show higher serum creatinine levels. Hyperglucagonemia might be the consequence of a simultaneous graft dysfunction and not the cause of impaired glucose tolerance. However, in our opinion, hyperglucagonemia is not exclusively attributable to renal dysfunction. Regarding the 10-year survival cohort, renal function was stable up to 10 years, whereas glucagon levels increased significantly. The data on glucagon release are especially interesting, since hyperglucagonemia and non-suppressible glucagon levels during hyperglycemia are important features in the pathogenesis of type 2 diabetes (27). That the $\alpha$ cells of denervated grafted islets show similar glucagon behavior as islets from type 2 diabetic patients is speculative. We cannot exclude that the pancreata under study were retrieved from donors who might have developed diabetes during lifetime. Recently, new therapeutic options for the treatment of type 2 diabetes with enhancement of incretin action (glucagon-like peptide-1 receptor agonists and dipeptidyl peptidase-4 inhibitors) emerged (28). These drugs display an inhibitory effect on glucagon secretion. It would be interesting to know whether or not these drugs influence long-term function of pancreas grafts .

The strength of this study is its strict prospective character with a long-term analysis of glucose metabolism in 38 type 1 diabetic patients after SPK. Despite a continuous increase of fasting glucose and $\mathrm{HbA}_{1 \mathrm{c}}$ levels and rates of impaired or diabetic glucose tolerance, a stability in $\beta$-cell function was demonstrated even in graft recipients with a segmental pancreas. Other aspects, especially glucagon secretion, might be responsible for the late aggravation of glucose metabolism.

\section{Acknowledgements}

We would like to thank Mrs K Aimer, Mrs C Baumann, and Mrs C Grünfeldt for excellent technical support. Further we would like to thank Dr A König and Mrs H Beranek for assistance in statistical problems and performance of statistical analyses.

\section{References}

1 Robertson P, Davis C, Larsen J, Stratta R \& Sutherland DE. Pancreas transplantation in type 1 diabetes. Diabetes Care 200427 S105.

2 Larsen JL. Pancreas transplantation: indications and consequences. Endocrine Reviews 200425 919-946.

3 Landgraf R. Pancreatic transplantation and its future role in diabetes management. Diabetic Medicine 199512 947-948.

4 Tyden G, Bolinder J, Solders G, Brattstrom C, Tibell A \& Groth CG. Improved survival in patients with insulin-dependent diabetes mellitus and end-stage diabetic nephropathy 10 years after combined pancreas and kidney transplantation. Transplantation $199967645-648$.

5 Smets YF, Westendorp RG, Van Der Pijl JW, De Charro FT, Ringers J, De Fijter JW \& Lemkes HH. Effect of simultaneous pancreas-kidney transplantation on mortality of patients with type-1 diabetes mellitus and end-stage renal failure. Lancet $19993531915-$ 1919.

6 Becker BN, Brazy PC, Becker YT, Odorico JS, Pintar TJ, Collins BH, Pirsch JD, Leverson GE, Heisey DM \& Sollinger HW. Simultaneous pancreas-kidney transplantation reduces excess mortality in type 1 diabetic patients with end-stage renal disease. Kidney International 200057 2129-2135.

7 Ojo a O, Meier-Kriesche HU, Hanson JA, Leichtman A, Magee JC, Cibrik D, Wolfe RA, Port FK, Agodoa L, Kaufman DB \& Kaplan B. The impact of simultaneous pancreas-kidney transplantation on long-term patient survival. Transplantation 2001 71 82-90.

8 Gruessner RW, Sutherland DE \& Gruessner a C. Mortality assessment for pancreas transplants. American Journal of Transplantation $200442018-2026$.

9 Sutherland DE, Najarian JS, Greenberg BZ, Senske BJ, Anderson GE, Francis RS \& Goetz FC. Hormonal and metabolic effects of a pancreatic endocrine graft. Vascularized segmental transplantation in insulin-dependent diabetic patients. Annals of Internal Medicine 198195 537-541.

10 Sutherland DE \& Gruessner A. Long-term function ( $>5$ years) of pancreas grafts from the international pancreas transplant registry database. Transplantation Proceedings 199527 2977-2980.

11 Lo A, Stratta RJ, Hathaway DK, Egidi MF, Shokouh-Amiri MH, Grewal HP, Winsett R, Trofe J, Alloway RR \& Gaber AO. Long-term outcomes in simultaneous kidney-pancreas transplant recipients with portal-enteric versus systemic-bladder drainage. American Journal of Kidney Diseases 200138 132-143.

12 Martin X, Feitosa Tajra LC, Benchaib M, Dawahra M, Lefrancois N \& Dubernard JM. Long-term outcome of pancreas transplantation. Transplantation Proceedings 199729 2423-2424.

13 Sudan D, Sudan R \& Stratta R. Long-term outcome of simultaneous kidney-pancreas transplantation: analysis of 61 patients with more than 5 years follow-up. Transplantation 2000 $69550-555$.

14 Alberti KG \& Zimmet PZ. Definition, diagnosis and classification of diabetes mellitus and its complications. Part 1: diagnosis and classification of diabetes mellitus provisional report of a WHO consultation. Diabetic Medicine 199815 539-553.

15 Jensen CC, Cnop M, Hull RL, Fujimoto WY \& Kahn SE. Beta-cell function is a major contributor to oral glucose tolerance in highrisk relatives of four ethnic groups in the U.S.. Diabetes $2002 \mathbf{5 1}$ 2170-2178.

16 Matthews DR, Hosker JP, Rudenski a S, Naylor BA, Treacher DF \& Turner RC. Homeostasis model assessment: insulin resistance and beta-cell function from fasting plasma glucose and insulin concentrations in man. Diabetologia $1985 \mathbf{2 8} 412-419$.

17 Matsuda M \& DeFronzo RA. Insulin sensitivity indices obtained from oral glucose tolerance testing: comparison with the euglycemic insulin clamp. Diabetes Care 199922 1462-1470.

18 Humar A, Gruessner RW \& Sutherland DE. Living related donor pancreas and pancreas-kidney transplantation. British Medical Bulletin 199753 879-891. 
19 Robertson RP. Consequences on beta-cell function and reserve after long-term pancreas transplantation. Diabetes 200453 633-644.

20 Kessler L, Passemard R, Oberholzer J, Benhamou PY, Bucher P, Toso C, Meyer P, Penfornis A, Badet L, Wolf P, Colin C, Morel P \& Pinget M. Reduction of blood glucose variability in type 1 diabetic patients treated by pancreatic islet transplantation: interest of continuous glucose monitoring. Diabetes Care 200225 2256-2262.

21 Christiansen E, Tibell A, Volund a A, Holst JJ, Rasmussen K, Schaffer L \& Madsbad S. Metabolism of oral glucose in pancreas transplant recipients with normal and impaired glucose tolerance. Journal of Clinical Endocrinology and Metabolism 1997 82 2299-2307.

22 Pfeffer F, Nauck MA, Drognitz O, Benz S, Von Dobschuetz E \& Hopt UT. Postoperative oral glucose tolerance and stimulated insulin secretion: a predictor of endocrine graft function more than 10 years after pancreas-kidney transplantation. Transplantation $2003 \mathbf{7 6} 1427-1431$.

23 Shim WS, Kim SK, Kim HJ, Kang ES, Ahn CW, Lim SK, Lee HC \& Cha BS. Decrement of postprandial insulin secretion determines the progressive nature of type-2 diabetes. European Journal of Endocrinology 2006155 615-622.
24 Weyer C, Bogardus C, Mott DM \& Pratley RE. The natural history of insulin secretory dysfunction and insulin resistance in the pathogenesis of type 2 diabetes mellitus. Journal of Clinical Investigation $1999 \mathbf{1 0 4} 787-794$.

25 Matte J, Fery F, Lankoande C, Schinohoritis P \& De Pauw L. Insulin secretion and glucose tolerance evolution in kidney-pancreas graft. Transplantation Proceedings 199527 3073-3074.

26 Marco J, Diego J, Villanueva ML, Diaz-Fierros M, Valverde I \& Segovia JM. Elevated plasma glucagon levels in cirrhosis of the liver. New England Journal of Medicine 1973289 1107-1111.

27 Mitrakou A, Kelley D, Mokan M, Veneman T, Pangburn T, Reilly J \& Gerich J. Role of reduced suppression of glucose production and diminished early insulin release in impaired glucose tolerance. New England Journal of Medicine 1992326 22-29.

28 Drucker DJ \& Nauck MA. The incretin system: glucagon-like peptide- 1 receptor agonists and dipeptidyl peptidase- 4 inhibitors in type 2 diabetes. Lancet 2006368 1696-1705.

Received 3 November 2006

Accepted 20 February 2007 